\title{
MALE SEX AND TUMOR DIAMETER ARE INDEPENDENT RISK FACTORS FOR RELAPSE OR PERSISTENT DISEASE IN DIFFERENTIATED THYROID CANCER
}

\author{
Aysun S. YIKILMAZ ${ }^{1}$, Umut MOUSA ${ }^{2}$, Asli NAR ${ }^{2}$ \\ ${ }^{1}$ Baskent University School of Medicine, Department of Internal Medicine, Ankara, Turkey \\ ${ }^{2}$ Baskent University School of Medicine, Department of Endocrinology and Metabolism, Ankara, Turkey \\ Received 07 July 2018, Accepted 06 Aug 2018 \\ hitps://doi.org/10.31688/ABMU.2018.53.3.11
}

\section{Abstract}

Background. Differentiated thyroid cancer (DTC) is one of the most frequently observed neoplasms today. Recurrence of DTC has been previously reported to be dependent on tumor characteristics, the tumor size, the presence of lymph node metastasis, the presence of extra thyroid invasion, the presence of distant metastasis, oncogenes such as B-RAF proto-oncogene, advanced age and male sex. However, many studies have failed to associate many of these data with relapse.

The objective of the study was to evaluate the relationship between some histopathological and morphological findings with thyroid cancer relapse or persistent disease in a cohort of 393 DTC patients.

Methods. We retrospectively analyzed 393 subjects with DTC, diagnosed in our institution between January 2000 and December 2010.

Results. Histopathological analysis indicated papillary carcinoma in 362 (92.1\%) subjects and follicular carcinoma in $31(7.9 \%)$ subjects. Eighty-two (20.9\%) of the subjects relapsed or had persistent disease. Male subjects had a higher trend for relapse (RR 1.739 \%95 CI: 1.059-2.856) p=0.029). 18.8\% of female subjects relapsed or had persistent disease, whereas the relapse rate was $30.4 \%$ in male subjects. Every $1 \mathrm{~cm}$

\section{Résumé}

Le sexe masculin et le diamètre tumoral sont des facteurs de risque indépendants pour une maladie persistante dans le cancer thyroïdien différencié

Contexte Le cancer différencié de la thyroïde (CDT) est l'un des néoplasmes les plus rencontrés à ce jour. La récurrence du CDT a été préalablement déclarée comme dépendante des caractéristiques de la tumeur, de la taille de la tumeur, de l'existence d'une métastase ganglionnaire, de la présence d'une invasion extra thyroïdienne, de la présence de métastases à distance, des oncogènes comme des proto-oncogènes B-raf, de l'âge et du sexe masculin. Cependant la plupart des études ont échoué à associer la grande partie de ces données avec la récurrence.

L'objectif de l'etude a été d'évaluer la relation entre certaines constatations histopathologiques et morphologiques et la récurrence du cancer de la thyroïde ou la maladie persistante dans une cohorte de 393 patients atteints de CDT.

Méthodes Nous avons rétrospectivement analysé 393 patients ayant le diagnostic de CDT entre janvier 2000 et décembre 2010.

Résultats L'analyse histopathologique a indiqué le carcinome papillaire chez $362(\% 92,1)$ sujets et 
increase in tumor size increased the risk of relapse by 25\% (RR=1.25, 95\% CI: 1.11-1.41, p<0.001). Male sex, nodule diameter, and tumor diameter were detected to be independent parameters for relapse or persistent disease $(\mathrm{p}=0.002 ; \mathrm{p}<0.0001, \mathrm{p}<0.001$ respectively).

Conclusion. We demonstrated that tumor diameter and male sex were the only parameters affecting relapse or persistent disease in our cohort. A possible reason for different reports from different studies may be non-standardization of study protocols and surgical cure rates.

Keywords: differentiated thyroid cancer, papillary carcinoma, follicular carcinoma, relapse. le carcinome folliculaire chez $31(7,9 \%)$ sujets. 82 (20,9\%) des sujets ont connu une récurrence ou une maladie persistante. Les patients masculins ont une tendance plus élevée de récurrence (RR 1,739\%, 95 CI: $1,059-2,856) p=0,029)$. 18,8\% des sujets féminins ont connu une récurrence ou une maladie persistante alors que le taux de récurrence est de $30,4 \%$ pour les sujets masculins. Chaque augmentation d'un centimètre de la taille de la tumeur augmente le risque de récurrence de 25\% ( $\mathrm{RR}$ 1,25, 95\% CI: 1,11-1,41, $\mathrm{p}<0,001)$. L'appartenance au sexe masculin, le diamètre du nodule et le diamètre de la tumeur ont été considérés comme des paramètres indépendants pour la récurrence ou pour la maladie persistante (respectivement $\mathrm{p}=0,002 ; \mathrm{p}<0,0001, \mathrm{p}<0,001)$.

Conclusion Nous démontrons ici que la tumeur et le sexe masculin sont les seuls paramètres affectant la récurrence ou la maladie persistante dans notre cohorte. Une raison possible des constats différents obtenus d'études diverses pourrait être la non-standardisation du protocole d'études et les taux de guérison chirurgicale.

Mots-clés: cancer différencié de la thyroïde, carcinome papillaire, carcinome folliculaire, récurrence.

However, a recent cohort study involving 209 subjects detected that cervical lymph node metastasis was the only independent parameter linked to papillary thyroid cancer relapse $e^{7}$. Male sex has been previously argued to be linked to adverse prognosis ${ }^{8}$.

Our group has previously detected that stimulated thyroglobulin levels above $5.6 \mathrm{ng} / \mathrm{mL}$ were associated with a 2.38-fold risk of relapse in subjects with DTC $^{3}$.

The OBJective OF THE STUDY was to assess the association between some tumor characteristics with recurrence and persistent disease, in the same study population.

\section{Material AND methods}

Between 2000 and 2010, 436 subjects were diagnosed with DTC in our institution, Baskent University School of Medicine, Department of Endocrinology and Metabolism, Ankara, Turkey. Subjects having distant metastasis at diagnosis were excluded. Subjects with at least one year follow up after the whole-body scan (WBS), performed 6-12 months after the initial treatment, were eligible for the study. We included 393 subjects who met these criteria in the study. 324 patients were female (82.4\%) and 69 were male $(17.6 \%)$ 
Total thyroidectomy was the initial treatment strategy in all subjects. Cervical ultrasonography (CUS) was performed by experienced endocrinologists, with a $10 \mathrm{MHz}$ probe (Logiq 5 Pro, GE medical systems, WI, USA). Prophylactic lymph node dissection was not performed. Lymph node dissection was only performed in subjects having radiologically evident pathological lymph nodes, determined by preoperative CUS.

According to the pathological analysis of the thyroidectomy material, subjects were reported to have a papillary microcarcinoma, classical papillary thyroid cancer (PTC), PTC follicular variant (FV), PTC Tall cell type, PTC insular type, classical follicular thyroid cancer (FTC) minimal invasive and classical FTC widely invasive.

Tumor size, multifocality, the presence of thyroid capsule invasion, the presence of extrathyroidal organ invasion, the presence of vascular invasion, the presence of lymphatic invasion, the presence of tumor cells at surgical sites, the presence of invasion of the vascular fascia and presence of tracheal invasion were evaluated by pathologists in our institution. Subjects were staged according to the tumor node metastasis (TNM) of the American Joint Committee on Cancer (AJCC) .

Subjects received radioactive iodine (RAI) ablation therapy, 6-8 weeks after surgery, following levothyroxine withdrawal. Subjects received $30-100 \mathrm{mCi}$ of radioactive iodine (RAI), for those without capsular invasion or cervical/distant metastasis. Subjects with an invasion of the thyroid capsule received $100-150 \mathrm{mCi}$ of RAI. Subjects with established cervical lymph node metastasis received $150-200 \mathrm{mCi}$ of RAI. After RAI therapy, levothyroxine was initiated, to suppress TSH levels $<0.1 \mathrm{ng} / \mathrm{mL}$ in the first year. Thyroglobulin ( $\mathrm{Tg}$ ) levels were defined to be positive if above $2 \mathrm{ng} / \mathrm{mL}$ in the stimulated period. Subjects were followed up with periodical Tg, thyroglobulin antibodies (Tg-ab), TSH levels, and CUS evaluations. A diagnostic 131-I whole body scan (WBS) was performed 9-12 months after the initial treatment.

Remission is defined as having a negative WBS performed 9-12 months after RAI therapy, having a negative stimulated $\operatorname{Tg}(<2 \mathrm{ng} / \mathrm{mL})$, negative thyroglobulin antibodies (Tg-ab), and normal CUS. For those with positive Tg-ab, remission is defined as having a negative WBS and normal CUS ${ }^{10}$. Subjects were also considered under remission in cases of low uptake in the thyroid bed with stimulated $\mathrm{Tg}<2 \mathrm{ng} / \mathrm{mL}$.

In subjects having positive $\mathrm{Tg}$ levels (i.e. $>2 \mathrm{ng} /$ $\mathrm{mL}$ ), recurrence was investigated by either WBS, CUS, computed tomography (CT), magnetic resonance imaging (MRI) and Positron Emission Tomography (PET). Suspicious cervical lymph nodes underwent a fine needle aspiration biopsy for cytological analysis.

\section{Statistical Analysis}

We used SPSS (Statistical Package for Social Sciences) version 15.0 for Windows. We used the Student's T-test and $\chi 2$ tests in addition to descriptive statistics when appropriate. Kaplan-Meier's curves were used for disease-free survival analysis. We used the logistic regression analysis for detecting independent variables for relapse. A two-sided $p$-value $<0.05$ was considered statistically significant.

\section{Results}

\section{General properties of the study group}

A total of 434 subjects were retrospectively analyzed. Seven subjects had established metastases at diagnosis, 20 subjects did not receive RAI for remnant ablation, and in 16 subjects recombinant human TSH (rhTSH) was employed, thus they were excluded, and the study was carried out with 393 subjects. Three hundred and ninety-three subjects with DTC were eligible for this study and were retrospectively analyzed. Demographic properties of the study group are summarized in Table 1.

According to the ATA 2009 risk stratification system, $343(87.2 \%)$ were low risk and 50 (12.8\%) were an intermediate risk ${ }^{10}$.

The mean age of the study group was $43.84 \pm$ 13.54 years (range $16-81$ years). A total of 214 out of 393 were below 45 years of age (54.4\%) and 179 subjects were above 45 (45.6\%). Three hundred and twenty-four subjects were female (82.4\%) and 69 $(17.6 \%)$ were male. The Female/Male ratio was 4.68. The mean maximum tumor size was $1.578 \pm 1.33 \mathrm{~cm}$ $(0.1-9 \mathrm{~cm})$. Thyroid capsule invasion was present in 117/393 (29.8\%) subjects.

Out of the 393 diagnosed subjects, 113 (28.8\%) had a single thyroid nodule and the remaining 280 (71.2\%) were multinodular. 130 subjects had multifocal disease (33.1\%). 43 subjects (10.9\%) had metastatic cervical lymph nodes at presentation.

Out of the 393 subjects, 366 underwent bilateral near-total thyroidectomy and 27 bilateral total thyroidectomy and central lymph node dissection.

Histopathology revealed that 362 (92.1\%) subjects had papillary thyroid cancer (PTC) and 31 had follicular thyroid cancer (FTC) (7.9\%). The most common histological subtype was classical PTC in 265 (67.4\%) subjects, PTC follicular variant (FV) in $88(22.4 \%)$ subjects, undifferentiated PTC in 9 subjects (2.4\%), micro-invasive FTC in 23 subjects $(5.9 \%)$ and invasive FTC in $8(2 \%)$ subjects. Seventy subjects $(17.8 \%)$ had histologically confirmed thyroiditis. 
Table 1. General characteristics of the study group

n (\%)

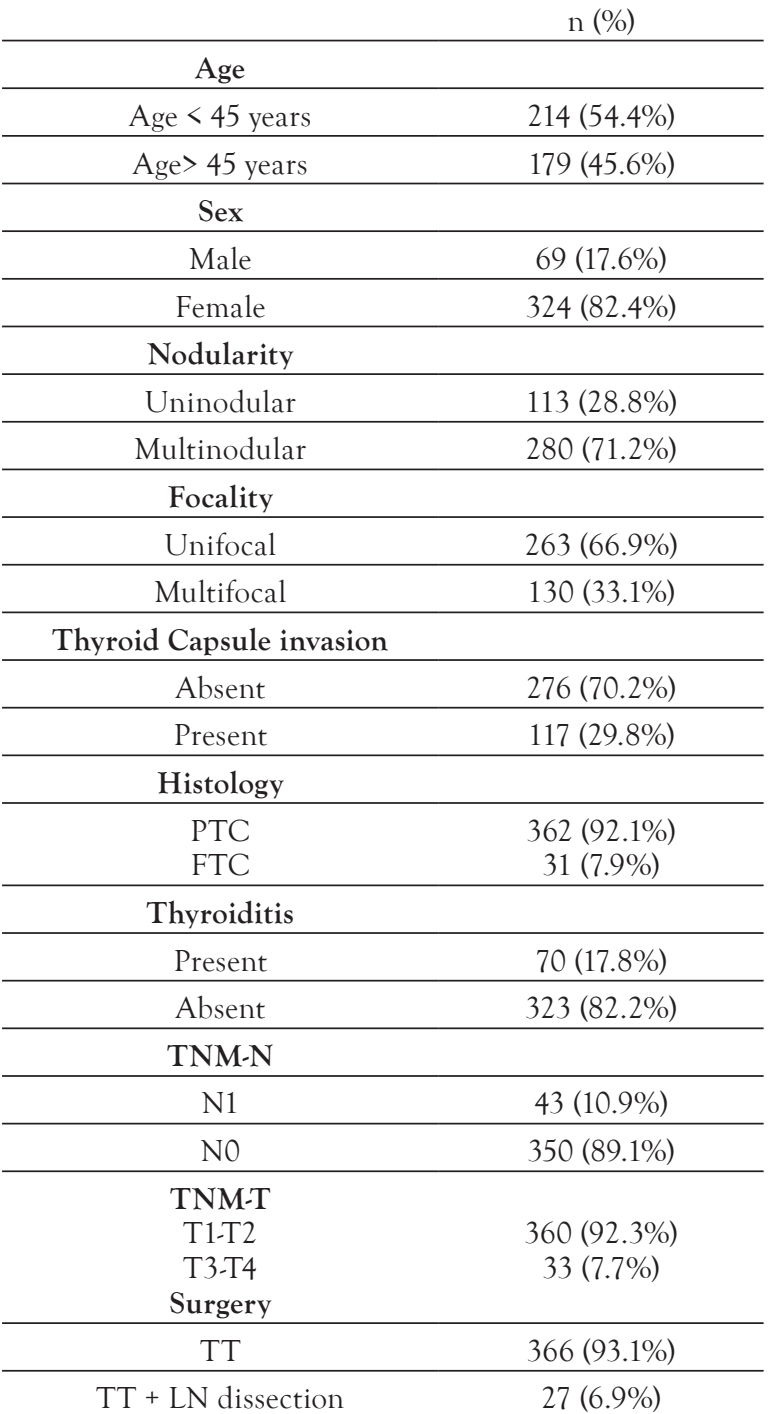

TNM: Tumor Node Metastasis; TT: Total Thyroidectomy; LN: Lymph Node; PTC: papillary thyroid cancer; FTC: Follicular thyroid cancer

\section{Association of risk factors with recurrence}

Subjects were followed up for a mean of 64.4 months after the primary surgical therapy (range 14-192 months). Eighty-two subjects relapsed or had persistent disease (20.9\%). The mean time to relapse was 16.7 months (4-63 months).

Male subjects had a higher trend for relapse (RR 1.739 \%95 CI: 1.059-2.856) p=0.029). 18.8\% of female subjects relapsed, whereas the relapse rate was $30.4 \%$ for male subjects.

Multinodularity increased significantly the risk of relapse (RR 1.933 (95\% CI 1.104-3.384) p=0.021). Out of the 393 diagnosed subjects, 113 (28.8\%) were uninodular and 280 (71.2\%) were multinodular. Sixteen of the uninodular group relapsed (14.15\%) whereas 66 of the multinodular group relapsed
(23.5\%). 263 subjects had unifocal disease, whereas 130 were multifocal. The relapse rates were similar among subjects with unifocal and multifocal disease (33/130 (25.3\%) vs 49/263 (18.6\%)) p>0.05. 108 subjects of the multinodular group had the multifocal disease (38.6\%).

The mean nodule diameter was $26.81 \pm 18.29$ $\mathrm{mm}$ in 82 subjects who relapsed and $21.38 \pm 12.86$ $\mathrm{mm}$ in 311 subjects under remission. This comparison was statistically significant $(p=0.013)$. According to the tumor sizes measured histopathologically, the mean tumor size was $2.04 \pm 1.63 \mathrm{~cm}$ in subjects who relapsed compared with a mean tumor size of $1.45 \pm 1.21 \mathrm{~cm}$ in subjects under remission. Every $1 \mathrm{~cm}$ increase in tumor size increased the risk of relapse by 25\% (RR=1.25, 95\% CI: 1.11-1.41, p<0.001).

The presence of thyroid capsule invasion increased the risk of relapse by 2 -fold $(R R=2.011,95 \%$ CI 1.3-3.11, $\mathrm{p}=0.002$ ). Thyroid capsule invasion was present in 117 subjects. Out of these, 36 relapsed (30.8\%). Relapse occurred in 46/276 subjects without capsular invasion (16.6\%).

The presence of cervical lymph node metastasis increased the risk of relapse by 2.76-fold ( $R R=2.76$, 95\% CI 1.63-4.66, p<0.001). 43 subjects had metastatic cervical lymph nodes. 18 of these relapsed (41.8 $\%)$. The disease-free survival was $17.2 \pm 1.75$ months in subjects with cervical lymph node metastasis, compared to $172.78 \pm 2.98$ months in subjects without cervical lymph node metastasis. The comparison was statistically significant $(\mathrm{p}<0.001)$.

Age, the presence of histological thyroiditis and histological subtypes were similar among subjects who relapsed compared to those under remission.

These risk models were adjusted for sex, multi-nodularity, tumor diameter, the presence of cervical lymph node metastasis, and the presence of thyroid capsule invasion. Male sex, nodule diameter, and tumor diameter were detected to be independent parameters for relapse $(p=0.002 ; p<0.0001, p<0.001$ respectively)

We used PET-CT to evaluate the presence of distant metastasis in 11 subjects with elevated Tg levels. We detected 7 metastases in this group (3 lung and 4 lymph nodes).

Out of the 393 subjects, 366 underwent bilateral near-total thyroidectomy and 27 bilateral total thyroidectomies together with central lymph node dissection. Subjects who underwent lymph node dissection had a shorter disease-free survival, which was attributable to the presence of lymph node metastasis compared to subjects undergoing thyroidectomy $(49.47 \pm 8.49$ months vs $60.75 \pm 3.64$ months, $\mathrm{p}<0.001)$. 


\section{Discussion}

In the present study, we demonstrated that tumor diameter and male sex were independent parameters for DTC relapse.

The proportion of male subjects in the present study was similar to that previously reported, ranging between $2 / 1$ and $4 / 1^{11,12}$. Our study population consisted of $82.4 \%$ female subjects and $17.6 \%$ male subjects. We demonstrated that male subjects had a 1.73-fold increase in the risk of relapse or persistent disease compared to female subjects. Some previous studies have reported similar findings, whereas many have failed to demonstrate such a relationship. A study by Sin-Ming Chow et al included 203 subjects with PTC in their study, which consisted of $86.7 \%$ female subjects and $13.3 \%$ male subjects. They established no relationship between gender and relapse ${ }^{13}$. Another study, which involved 1516 subjects with PTC, revealed that lung metastasis was more frequent in male subjects ${ }^{14}$. Like this study, Clark et al established that distant metastasis was more frequently observed in male subjects ${ }^{15}$. A study published in 2012, involving 435 subjects with DTC, demonstrated that both relapse and mortality were higher in male subjects.

In the present study, tumor diameter was associated with relapse or persistent disease. Every 1 $\mathrm{cm}$ increase in tumor size increased the risk of relapse by 25\% ( $R R=1.25,95 \%$ CI: 1.11-1.41, p <0.001). Although some studies have not associated tumor diameter with relapse, many studies defend this relationship and a Korean study has shown that a tumor size $>1.8 \mathrm{~cm}$, together with cervical lymph node metastasis and bilateral disease, were independent risk factors ${ }^{6}$.

There was no relationship between multifocality, the presence of histologically confirmed thyroiditis, age, histological subtype, and relapse. Multifocality has previously been argued as an adverse prognostic factor. A study by Pellegrini et al established that bilateral disease in subjects with PTC was a risk factor for relapse ${ }^{16}$. Baudin et al established that the number of histological foci significantly increased the risk of relapse $^{17}$. Similar to our results, Ito Y et al established no such relationship ${ }^{18}$.

Souza et al determined in their study that the presence of autoimmune thyroiditis had a favorable effect on PTC prognosis ${ }^{19}$, whereas similar to our study Huang et al determined that presence of thyroiditis had no effect on PTC and FTC prognosis ${ }^{20}$.

We established that the presence of capsule invasion increased the risk of relapse by 2.01-fold. A study by Furlan et al established that capsule invasion was not associated with prognosis in a cohort of 350 PTC $^{21}$. Haq et al also observed similar findings ${ }^{22}$.

An interesting finding of our study was that multinodularity increased the risk of relapse by 1.93 -fold. Kappur et al established that subjects with a solitary tumor with a multinodular thyroid gland had a higher rate of metastasis compared to those with a solitary nodule ${ }^{23}$. However, in the multivariate analysis, this factor was not defined to be an independent risk factor.

\section{Conclusions}

Many factors have been incriminated to increase the risk of thyroid cancer relapse and conflicting results have been obtained. We demonstrated in our study that tumor diameter and male sex were the only parameters affecting relapse or persistent disease in our cohort. A possible reason for different reports from different studies may be non-standardization of study protocols and surgical cure rates.

\section{Compliance with Ethics Requirements:}

„The authors declare no conflict of interest regarding this article"

"The authors declare that all the procedures and experiments of this study respect the ethical standards in the Helsinki Declaration of 1975, as revised in 2008(5), as well as the national law. Informed consent was obtained from all the patients included in the study"

This study was approved by the Baskent University Research Committee

"No funding for this study"

\section{References}

1. https://seer.cancer.gov/statfacts/html/thyro.html

2. Puxeddu E, Filetti S. The 2009 American Thyroid Association Guidelines for management of thyroid nodules and differentiated thyroid cancer: progress on the road from consensus- to evidence-based practice. Thyroid, 2009; 19: 1167-214.

3. Mousa U, Yikilmaz AS, Nar A. Stimulated thyroglobulin values above $5.6 \mathrm{ng} / \mathrm{ml}$ before radioactive iodine ablation treatment following levothyroxine withdrawal is associated with a 2.38-fold risk of relapse in Tg-ab negative subjects with differentiated thyroid cancer. Clin Transl Oncol. 2017, 19(8):1028-1034.

4. Joseph KR, Edirimanne S, Eslick GD. Multifocality as a prognostic factor in thyroid cancer: A meta-analysis. Int $J$ Surg. 2018, 50:121-125.

5. Kauffmann RM, Hamner JB, Ituarte PHG, Yim JH. Age greater than 60 years portends a worse prognosis in patients with papillary thyroid cancer: should there be three age categories for staging? BMC Cancer. 2018, 18(1):316

6. Yul H, Jung MK, Young JP, et al. Long-term recurrence of small papillary thyroid cancer and its risk factors in a 
Korean multicenter study. Journal Clinical Endocrinol Metab, 2017; 102 (2)625-633.

7. Domínguez JM, Nilo F, Martínez MT, et al. Papillary thyroid microcarcinoma: characteristics at presentation, and evaluation of clinical and histological features associated with a worse prognosis in a Latin American cohort. Arch Endocrinol Metab. 2018, 62(1):6-13.

8. Hsieh SH, Chen ST, Hsueh C, Chao TC, Lin JD. Gender-specific variation in the prognosis of papillary thyroid cancer TNM stages II to IV. Int J Endocrinol. 2012;2012:379097.

9. Wittekind C, Compton CC, Greene FL, Sobin LH. TNM residual tumor classification revisited. Cancer. 2002 94(9):2511-6.

10. Puxeddu E, Filetti S. The 2009 American Thyroid Association Guidelines for management of thyroid nodules and differentiated thyroid cancer: progress on the road from consensus- to evidence-based practice. Thyroid. 2009; 19: $1167-214$.

11. Merhy J, Driscoll HK, Leidy JW, Chertow BS. Increasing incidence and characteristics of differentiated thyroid cancer in Huntington, West Virginia. Thyroid 2001; 11: 1063-69.

12. Clark JR, Lai P, Hall F, Borglund A, Eski S, Freeman JL. Variables predicting distant metastases in thyroid cancer. Laryngoscope. 2005; 115: 661-7.

13. Chow SM, Law S.C.K, Au S.K, et al. Changes in clinical presentation, management and outcome in 1348 patients with differentiated thyroid carcinoma. Clin Oncol 2003; 15: 329-336.

14. Lin JD, Chao TC, Chou SC, Hsueh C. Papillary thyroid carcinomas with lung metastases. Thyroid. 2004; 14: 1091-6.
15. Clark JR, Lai P, Hall F, Borglund A, Eski S, Freeman JL. Variables predicting distant metastases in thyroid cancer. Laryngoscope. 2005; 115: 661-7.

16. Pellegriti G, Scollo C, Lumera G, Regalbuto C, Vigneri R, Belfiore A: Clinical behavior and outcome of papillary thyroid cancers smaller than $1.5 \mathrm{~cm}$ in diameter: study of 299 cases. J Clin Endocrinol Metab 2004; 89: 3713-20.

17. Baudin E, Travagli JP, Ropers J. Microcarcinoma of the thyroid gland: the Gustave- Roussy Institute experience. Cancer 1998; 83: 553-59.

18. Ito Y, Miyauchi A. Prognostic factors of papillary and follicular carcinomas in Japan based on data of Kuma hospital. J Thyroid Res. 2012; 2012: 973497.

19. Souza SL, Montalli da Assumpcao LV, Ward LS. Impact of previous thyroid autoimmune diseases on prognosis of patients with well-differentiated thyroid cancer. Thyroid 2003; 13: 491-495.

20. Huang BY, Hseuh C, Chao TC, Lin KJ, Lin JD. Well-differentiated thyroid carcinoma with concomitant Hashimoto's thyroiditis present with less aggressive clinical stage and low recurrence. Endocr Pathol. 2011; 22: 144-9.

21. Furlan JC, Bedard YC, Rosen IB. Significance of tumor capsular invasion in well- differentiated thyroid carcinomas. Am Surg. 2007; 73: 484-91.

22. Haq M, Harmer C. Differentiated thyroid carcinoma with distant metastases at presentation: prognostic factors and outcome. Clin Endocrinol (Oxf). 2005; 63: 87-93.

23. Kapur MM, Sarda AK, Bal S, Sood S. Carcinoma of the thyroid: differential behavior in solitary and multinodular tumours. Br J Surg. 1986; 73: 894-5. 